\title{
A Mathematical Method to Keep The Temperature In The Bathtub
}

\author{
Huinian $\mathrm{Li}^{1, \mathrm{a}}$,Shuting $\mathrm{Li}^{2, \mathrm{~b}}$ and Jiong Zhang ${ }^{2, \mathrm{c}}$ \\ ${ }^{1}$ North China Electric Power University, Baoding ,China \\ ${ }^{2}$ North China Electric Power University, Baoding ,China \\ ${ }^{3}$ North China Electric Power University, Baoding ,China

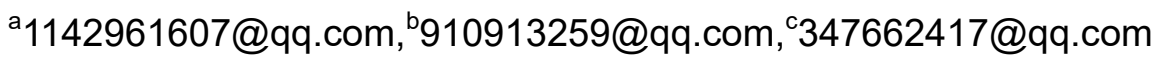

Keywords: Lumped Parameter Model, Runge-Kutta Method, Hot Bath

\begin{abstract}
In this paper, we do the best to extend the time of bathing without wasting too much water. In the Lumped Parameter model ${ }^{[1]}$, we predict the change of temperature by the use of Runge-Kutta method. We also consider the heat dissipation between the water and the bathtub wall as well as the air. And we discuss the change of temperature under different height of water surface. In our opinion, when a person is sitting in the tub, he just gets heat energy from water. We add a new equation of conservation of energy. Compared with the heat dissipation on the water, the body has less influence on the temperature of water. A person is in motion instead of stationary when bathing. In other to correct the evaporative coefficient of water, we introduce a correction coefficient (we call it $\alpha$ ). Under the depth of 0.43 meters, we can determine to reach the value of the correction coefficient $(\alpha)$ of $38^{\circ} \mathrm{C}$ within 15 minutes, where $\alpha=1.15$. After researching the relationship between different rate of drainage and temperature, we use $\alpha$ to predict the time arriving at $38^{\circ} \mathrm{C}$ for the second time. Compared with the longest suitable bathing time, it is longer than 30 minutes in general. It can be proved that our strategy is able to keep the temperature throughout the bathtub and as close as possible to the initial temperature without wasting too much water.
\end{abstract}

\section{Introduction}

A bathtub, bath or tub (informal), a water pipe equipment for the use of bathing or showering, is usually equipped in the bathroom .Namely, it is a large capacity for holding water in which a person may bathe. A number of modern bathtubs are made of fiberglass or acrylic, but alternatives are available in enamel on steel or cast iron. Recently, because of the growing popularity of acrylic bathtub with heating system, most different shapes are becoming available. The analysis of the comfort of bathing has been a universal concern. Moreover, there have been a lot of researches into the studies of the standard and shape of the bathtub. The problem requires us to do several jobs to determine the best strategy the person in the bathtub can adopt to keep the temperature even throughout the bathtub.

We need to research the change trend of water temperature with a person in the water, who has motions. In this problem, we need to consider the heat dissipation between water and air as well as that between water and the surface tub. Further, we consider the influence from the parameter with some motions in the bathtub. 




Figure 1.Dimensions of a typical bathtub

http://de-lune.com/dimensions-of-a-typical-bathtub/

\section{Model Developing}

\subsection{Introduction}

This model is mainly solving the problem of a person's motions. Based on the Lumped Parameter model, we simulate the process of a person with motions in the water. Considering that a person's motions can have influence on the heat dissipation on the surface water, we determine to correct the coefficient $\Phi_{\text {out } 1}$. We also determine the correction factor as $\alpha$, whose name is motion correction coefficient. Referring to the documents and information ${ }^{[2]}$, we know that there are three forms of hot water's heat dissipation toward the air, like thermal convection, evaporative heat dissipation, radiating heat loss.

\subsection{The Foundation of Model}

As for Zero dimensional unsteady heat conductors, the whole heat conductor (water) is regarded as control volume. The relationship of conservation of energy follows the equation of conservation of energy within a closed control container. According to the concept of Lump of water, the increasing rate of thermodynamics energy of per unit time can be expressed as follow:

$$
\frac{d U}{d \tau}=\int_{v} \rho c \frac{\partial t}{\partial \tau} d V=\rho c V \frac{d t}{d \tau}
$$

Therefore, the equation of conservation of energy for Lump of water is follow. The corresponding equation of equation (1) is

$$
\rho c V \frac{d t}{d \tau}=\Phi_{\text {in }}-\Phi_{\text {out }}+V \dot{\Phi}
$$

Where, $\dot{\Phi}$ is the strength of the inner heat source.

Due to the Bowen ratio ${ }^{[3]}$, we know

$$
\frac{\lambda}{\beta}=b=\frac{P_{a} C_{p}}{0.623 \gamma}
$$

Where

$$
\begin{aligned}
& P_{a} \text { is atmospheric pressure with the units of } h P a \\
& C_{p} \text { is the dry air specific heat with the units of } 1.005 \mathrm{~kJ} / \mathrm{kg} \cdot{ }^{\circ} \mathrm{C} \\
& \gamma \text { is the water heat of vaporization with the units of } 2500 \mathrm{~kJ} / \mathrm{kg}
\end{aligned}
$$

Looking at the data ${ }^{[4]}$, we can learn that the suitable bathing time is 15 minutes to 30 minutes. Therefore, we consider that the body will perceive the water cooler after 15 minutes' bathing.

Based on the model, when a person sits into the bathtub, the hot water transmits the heat energy to the body, and 


$$
\Phi=C_{p} m(t-38)
$$

At the moment, we can improve a thermal conductivity model. Its differential equation is following:

$$
\begin{array}{r}
\rho c V \frac{d t}{d \tau}=-\alpha \frac{2.7(t-\theta)^{1 / 3} P_{a} A_{1}}{0.623 \gamma}\left[h(t)-h_{\theta}\right]-\frac{A_{2} \lambda\left(t-t_{0}\right)}{\delta}-4 \lambda S\left(t-t_{0}\right)-C_{p} m(t-38) \\
\text { Table } 1 \text { Results of the process of exploration about } \alpha
\end{array}
$$

\begin{tabular}{ccccc}
\hline alefa & B1 & B2 & B3 & time \\
\hline 1.1 & 42.77 & -0.0064 & $10.26 \mathrm{E}-07$ & 14.41 \\
1.2 & 42.80 & -0.0059 & $9.35 \mathrm{E}-07$ & 16.22 \\
1.15 & 42.78 & -0.0062 & $9.81 \mathrm{E}-07$ & 14.99 \\
\hline
\end{tabular}

\subsection{Solution and Result}

Once going into the bathtub, the water will soak in two-thirds of the body. After filling up with water, it will soak in 3/4 of the body. Now, we want to discuss the time that temperature will reduce until $38^{\circ} \mathrm{C}$ for the second time with the different rate of drainage. As we learn the height of water is 0.43 meters, it is the list that the time of the temperature reducing until $38^{\circ} \mathrm{C}$ change with the rate of drainage (Shown in the table 2). The curve graph is in the Figure 2.

\begin{tabular}{lll}
$\begin{array}{l}\text { Table } 2 \text { Results of Arriving } 38^{\circ} \mathrm{C} \\
\text { The rate of } \\
\text { drainage }\end{array}$ & $\begin{array}{l}\text { The temperature } \\
\text { after adding water }\end{array}$ & $\begin{array}{l}\text { Arriving } 38^{\circ} \mathrm{C} \text { for } \\
\text { the second time }\end{array}$ \\
\hline 0.1 & 40.9356 & 30.78 \\
0.15 & 41.1224 & 31.54 \\
0.20 & 41.3092 & 32.27 \\
0.25 & 41.4959 & 33.01 \\
0.30 & 41.6827 & 33.71 \\
\hline
\end{tabular}

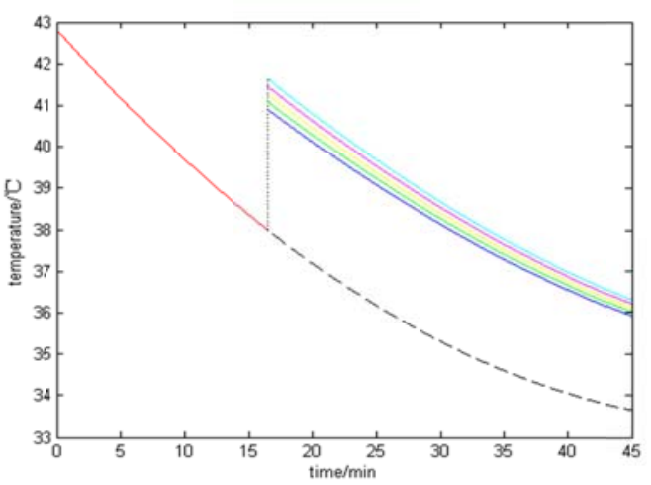

Figure 2

\subsection{Strength and Weakness}

(1) We can push out the correction coefficient with motions, and solve the problem that the motions of body have influence on the temperature.

(2) The correction coefficient is a constant.

\section{Conclusion}

From the above Table 1, we know the height of the water is 0.43 with a person sitting in the bathtub. When the temperature reduces until $38^{\circ} \mathrm{C}$ with a person moving in the tub, it consumes 900 seconds, namely 15 minutes. We calculate the correction coefficient $\alpha=1.15$.

According to the result, we can find that the rate of drainage has influence the time of the temperature reducing until $38^{\circ} \mathrm{C}$. 


\section{References}

[1] Lumped element model https://en.wikipedia.org/wiki/Lumped element model \#Lumped element model

[2] ZHAO Zhen-guo, Enthalpy difference formula for calculating heat dissipation on water surface and its use, China Institute of water Resources and Hydropower Research, Beijing, 2004, ,(1):1-2

[3] Bowen L S . The ratio of heat losses by conduction and by evaporation from any water surface [J]. phys. Rev .,1926,27:779-787.

[4] How to Take a Bath http://www.wikihow.com/Take-a-Bath 